\title{
Energy requirements of breeding great cormorants Phalacrocorax carbo sinensis
}

\author{
David Grémillet, Dagmar Schmid, Boris Culik
}

Institut für Meereskunde, Abt. Meereszoologie, Düsternbrooker Weg 20, D-24105 Kiel, Germany

\begin{abstract}
Cormorants and humans are purported to compete for fish resources. Recent increases in cormorant populations in western Europe have led to new conflicts between fishermen and nature conservationists, a situation which has stimulated research into the food requirements of these seabirds. However, most dietary studies are based on stomach content or pellet analysis. Both these methods are biased. We used a time-budget model to calculate the energy requirements of great cormorants Phalacrocorax carbo sinensis breeding in Schleswig-Holstein, Germany. The time budgets of the birds were recorded for different breeding phases and the energetic costs of the different activities determined through respirometric measurements or by using values derived from the literature. The food requirements of great cormorants during incubation were calculated to be $238 \mathrm{~g} \mathrm{adult} \mathrm{f}^{-1} \mathrm{~d}^{-1}$ These requirements rise to $316 \mathrm{~g} \mathrm{~d}^{-1}$ during the rearing of young chicks and to $588 \mathrm{~g} \mathrm{~d}^{-1}$ during rearing of downy chicks. Human disturbance causing great cormorants to fly off their nests entails an additional consumption of $23 \mathrm{~g}$ fish per bird or ca $23 \mathrm{~kg}$ per disturbance event for a typical colony.
\end{abstract}

KEY WORDS: Phalacrocorax carbo sinensis Time/energy budget - Food requirements Breeding season D Disturbance

\section{INTRODUCTION}

The great cormorant Phalacrocorax carbo occurs on all the world's continents and is considered by some to be a major competitor with humans in certain areas (Deufel 1986). This apparent competition resulted in the destruction of most European colonies of the great cormorant $P$. carbo sinensis at the end of the last century (Dif 1982). Persecution has decreased since World War II, after which cormorants became protected. The enhanced protection and, to a lesser extent, the general eutrophication of coastal and freshwater ecosystems have recently led to a rapid increase in the European population of this bird (Hashmi 1988, Suter 1989). This development has been followed by a conflict between nature conservationists and fishermen concerning the influence of cormorants on coastal and freshwater fish populations (Knief \& Witt 1983). Consequently, cormorant research has focused on the feeding ecology of these seabirds with the aim of better understanding of their position in the aquatic ecosystem (see Müller 1986, Worthmann \& Spratte 1990,
Marteijn \& Dirksen 1991). In most studies that directly concern $P$. carbo sinensis, daily food intake has been calculated from pellet or stomach content analyses. However, both of these methods have been shown to be biased (Grémillet \& Plös 1994). In the present study we determined the daily energy requirements of great cormorants breeding in Schleswig-Holstein (Germany) using a time budget analysis as described by Weathers et al. (1984). This method allowed us to calculate the theoretical food intake per bird per day for the different breeding phases.

\section{METHODS}

Time budgets. Time budgets of great cormorants breeding at Lake Selent $\left(54^{\circ} 25^{\prime} \mathrm{N}, 10^{\circ} 30^{\prime} \mathrm{E}\right.$; Fig. 1), Germany, were determined during June 1993. Groundbreeding birds were observed from dawn to dusk from a hide set $5 \mathrm{~m}$ from the nests. Bird activity patterns were recorded using a manual field computer (Husky Hunter II). Activities such as resting, preening, nest 


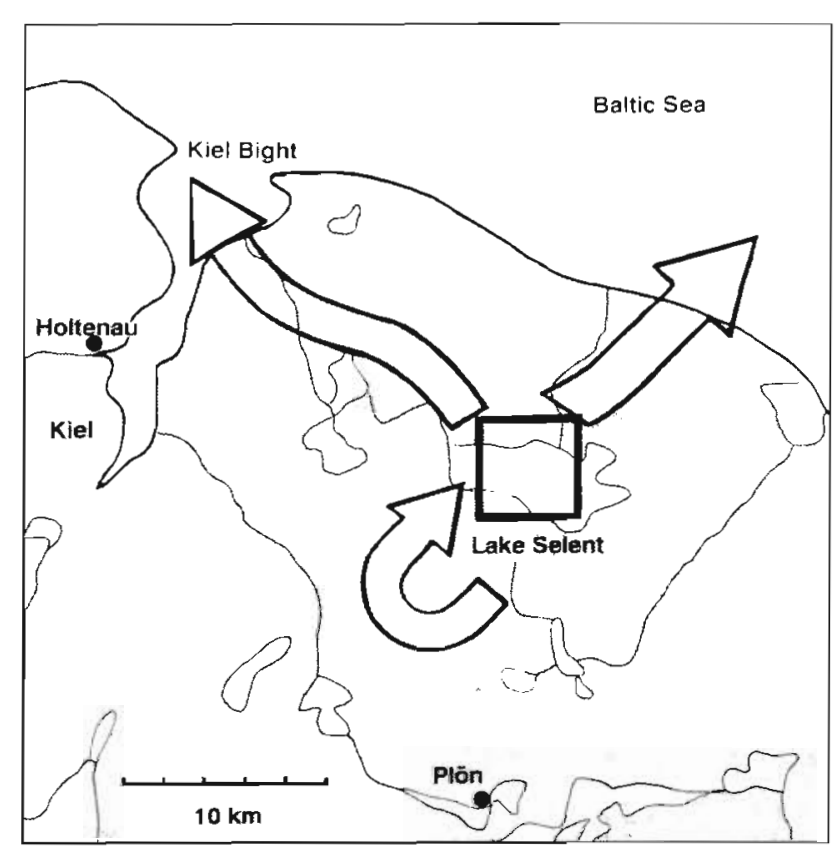

Fig. 1. The study area near Kiel, Germany. Arrows show flight routes of the cormorants to the different fishing grounds (Kieckbusch \& Koop 1992). Locations of weather stations are also indicated $(\bullet)$

building, and chick feeding were registered for incubating birds and for birds raising small $(<10 \mathrm{~d})$ or downy chicks. The duration of the foraging trips and their incidence per day were also recorded. Minor activities such as nest defence, walking, wing stretching, and shivering were grouped in a single category.

Great cormorants outside the colony may swim, stretch their wings, preen, and rest. The swimming time per foraging trip was determined during June 1993 by direct observation (binoculars $10 \times 50$; maximum distance $300 \mathrm{~m}$ ) of great cormorants fishing along the coast of the Baltic Sea. The observed birds were identified as breeding adults by their dark black body feathers and the white patches on their upper legs.

The flight time per foraging trip was calculated using observations from Menke (1986) and Kieckbusch \& Koop (1992) of the flight routes of cormorants breeding at Lake Selent. The areas in which these cormorants usually feed are the lake itself, the outer Kiel Fjord and the Kiel Bight (Fig. 1). Assessment of the diet of the birds by Kieckbusch \& Koop (1993) showed that they consume nearly $50 \%$ marine and $50 \%$ freshwater fish. We thus assumed that the cormorants use the sea for a fishing ground half of the time and the lake the other half of the time. The birds were assumed to fly the shortest route from the colony to the feeding site to avoid flight other than this while at sea, to feed only once dur- ing each trip, and to have comparable swimming times when feeding on Lake Selent and at sea. Recent radiotracking data (Grémillet unpubl.) and direct observations (Menke 1986) confirm these assumptions. The duration of wing stretching was derived from Menke (1986). Resting and preening times outside the colony were assumed to be equal to foraging time as derived from observations at the colony, minus flight, swimming and wing-stretching time.

Energy costs. The resting metabolic rate (RMR) and the energy costs of preening were determined through measurement of oxygen consumption. All respirometric measurements were performed during September 1993 at the Heimattierpark Neumünster, Germany. Five fasting great cormorants were kept for at least $2 \mathrm{~h}$ in a $100 \mathrm{l}$ respiration chamber in the dark within their thermoneutral zone, their oxygen consumption was measured using an open respirometric system and an Oxygor $6 \mathrm{~N}$ oxygen analyser (Maihak, Hamburg; for details see Culik et al. 1990). The birds were particularly tame and thus quickly became accustomed to the respiration chamber. They typically first preened, after which they stood quietly. We used data from standing birds as this is the normal resting position in cormorants, even during the night. The RMR was calculated from the lowest measured oxygen consumption, which was in general attained after $60 \mathrm{~min}$. The RMR at night or during periods of sunshine was assumed to be $75 \%$ or $90 \%$, respectively, of the RMR measured in the respiration chamber (Aschoff \& Pohl 1970, Dunn 1976). The lower critical temperature in great cormorants is $9^{\circ} \mathrm{C}$, calculated after Kendeigh et al. (1977). Since field temperatures of below $9^{\circ} \mathrm{C}$ occurred for less than $5 \%$ of the total breeding time, birds were assumed to be within their thermoneutral zone for the entire breeding season.

Great cormorants usually reuse old nests (Kortlandt 1991). Nest building therefore mainly consists of the reorganisation of nest material. This activity pattern involves head and beak movements which are similar to the movements of preening. We thus assumed that the energy costs of nest building were the same as for preening

The energy costs of egg production can be derived from the energy content of the eggs (Kendeigh et al. 1977). Cooper (1987) additionally showed that the energy content of eggs from the bank cormorant Phalacrocorax neglectus was linearly related to their fresh weight. We therefore used the relationship between fresh egg weight and egg energy content given by Cooper (1987) to determine the energy content of great cormorant eggs. The mean fresh weight was taken to be $46 \mathrm{~g}$ (Dif 1982). We also considered an efficiency of $70 \%$ for egg production (King 1973) and a mean clutch size of 3 (Menke unpubl.) for great cormorants breeding at Lake Selent. 
The energy costs of incubation were determined according to Kendeigh et al. (1977) using a mean clutch size of 3 , a mean egg weight of $46 \mathrm{~g}$ and mean egg and nest temperatures of 33.4 and $28^{\circ} \mathrm{C}$ respectively (Cooper 1987). A mean egg coverage of $80 \%$ (Ackerman \& Seagrave 1984) and a constant incubation were also assumed. The energy costs of brooding were also calculated according to Kendeigh et al. (1977) assuming a mean brood size of 2 chicks (Gregersen 1991), a mean chick weight of $165 \mathrm{~g}$ (Platteeuw et al. in press), a mean chick body temperature of $40^{\circ} \mathrm{C}$ (Grémillet unpubl.), and a constant mean coverage of $80 \%$.

Further energy expenditure occurs while parents feed chicks. This activity was determined to cause RMR to rise up to 1.10 in Adélie penguins and to 1.53 in Adélie penguin chicks (Culik 1995). As both regurgitation in adults and begging in chicks are very similar in penguins and cormorants, we consider that the energy requirement of cormorants for this activity can be derived from the measurements made by Culik (1995) in Adélie penguins.

The energy requirements of great cormorant chicks were derived from respirometric measurements made by Dunn (1976) on chicks of double-crested cormorant Phalacrocorax auritus. Growth curves of great and double-crested cormorant chicks are very similar Additionally, the species live under comparable meteorological conditions (Schleswig-Holstein and New Hampshire, USA). Thus, according to Klaassen \& Drent (1991), the energy requirements of great cormorant chicks can be derived from Dunn (1976).

As in the case of the adult birds, we assumed chicks incur a reduction in RMR of $25 \%$ during the night (Aschoff \& Pohl 1970) and of 10\% during sunny conditions (Dunn 1976). This last assumption was considered valid only for chicks older than $10 \mathrm{~d}$, as younger chicks are constantly covered by their parents.

Flight costs were determined according to Pennycuick (1989) for a body mass of $2230 \mathrm{~g}$ (Dif 1982), a wingspan of $136 \mathrm{~cm}$ (Géroudet 1959) and a flight speed of $70 \mathrm{~km} \mathrm{~h}^{-1}$ (Van Dobben 1952, Géroudet 1959). Different 'parasitic' food loads were also considered.

The costs of underwater swimming and of resting on the water surface were determined through respirometic measurements using methods described in Culik \& Wilson (1991). These measurements were also conducted at the Heimattierpark Neurnünster, using the same analytic system as for the determination of RMR and metabolic costs of preening. Five tame great cormorants were trained to voluntarily enter a $13 \mathrm{~m}$ long canal ( $1 \mathrm{~m}$ wide and $1 \mathrm{~m}$ deep) and to swim from one end of the enclosure to the other. The canal was equipped with a respiration chamber at each end, whereas the rest of the surface was entirely covered with transparent PVC plates. This guaranteed that the birds could breathe only in the chambers. Each experiment was conducted for 40 to $72 \mathrm{~min}$ (mean: $56 \mathrm{~min}$ ), during which the activity patterns of the birds and their position in the canal relative to colour marks on the PVC plates were recorded by an observer with a walkman with quartz-based time speed. The birds were removed when they stopped swimming and remained for longer than 5 min in one of the chambers.

The energy requirements of wing stretching were determined using a relation given by Hennemann (1983). We assumed a mean body weight of $2230 \mathrm{~g}$ (Dif 1982 ), a mean body temperature of $40^{\circ} \mathrm{C}$ (Gremillet \& Plös 1994) and a mean air temperature of $12.4^{\circ} \mathrm{C}$ (meteorological station Kiel-Holtenau).

Additional energy costs are required for food warming (Wilson \& Culik 1991). These were calculated using a standard thermodynamic relation:

$$
E=m \times S H C \times\left(T_{1}-T_{2}\right)
$$

where $E$ is the energy required to warm the food in joules, $m$ the mass of the food ingested in grams, SHC the specific heat capacity of the food (taken to be $4 \mathrm{~J}$ $\left.\mathrm{g}^{-1}{ }^{\circ} \mathrm{C}^{-1}\right), T_{1}$ the stomach temperature of the bird (taken to be $40^{\circ} \mathrm{C}$ based on Grémillet \& Plös 1994) and $\mathrm{T}_{2}$ the temperature of the prey, i.e the water temperature for fish (taken to be $11.3^{\circ} \mathrm{C}$; Schweimer 1978).

A literature review by Grémillet \& Schmid (1993) showed that the mean daily food intake in great cormorants as determined by pellet and stomach content analysis is $358 \mathrm{~g}$. We thus assumed that the birds from Lake Selent had to warm this quantity of fish every day. Some of this energy can be provided by the bird during hard exercise since $75 \%$ of the energy metabolised is liberated as heat (Schmidt-Nielsen 1983). cormorants need about 45 min to warm $358 \mathrm{~g}$ of food (calculated from Grémillet \& Plös 1994). We noted that, post ingestion, birds usually stretched their wings for a few minutes and then divided their time between resting and preening. Knowing the energetic costs of each of these activities, it is possible to calculate how much heat the bird will be able to reuse for prey warming, assuming that all heat produced will be used to warm the stomach contents. The real energetic costs of eating cold food will be then equal to the costs of warming, minus the heat produced immediately after fishing. Substantial amounts of heat are also generated while flying. However, it is difficult to predict how much heat can then be used for food warming as the birds also lose much heat due to air cooling effects.

No data concerning body weight variations in breeding great cormorants were available. We thus assumed that all energy requirements of breeding birds have to be covered by their food intake during the breeding season and are not taken from fat reserves. 
Following Brugger's (1993) calculations for doublecrested cormorants, the assimilation efficiency of great cormorants was taken to be $77 \%$. Kieckbusch \& Koop (1993) determined by pellet analysis that great cormorants breeding at Lake Selent feed on a very wide range of prey items including perch Perca sp., white fish, cod Gadus morhua and other marine fish such as sandeel Ammodytes sp., whiting Merlangius merlangus, herring Clupea harengus, plaice Pleuronectes platessa and viviparus blenny Zoarces viviparus. Cormorants may also take shore crabs Carcinus maenas. The mean energy content of their food was thus calculated to be $4.0 \mathrm{~kJ} \mathrm{~g}^{-1}$ (taken from Kieckbusch \& Koop 1993. Hislop et al. 1991 and Sidwell 1981, where mass refers to fresh mass of food).

Weather conditions, especially air temperature and wind speed, have been shown to influence the metabolism of free-living birds so as to make the use of respirometric measurements inadequate for the calculation of the daily energy budget (Kendeigh \& Blem 1974) We consequently recorded meteorological conditions, such as air and water temperature and wind speed and light intensity, at the breeding site and at the zoo. These measurements were made every 10 min at a height of $1.5 \mathrm{~m}$ using a portable micrometeorological station (Grant Instruments). Mean weather data over the complete breeding season (April to July) at the feeding grounds and at the breeding colony were taken from the weather stations Kiel-Holtenau and Plön respectively (Fig. 1). Water temperatures at the fishing areas were taken from Schweimer (1978).

Air temperature in the respiration chambers was also recorded using an independent temperature probe (Single Channel Unit Processor; Driesen \& Kern).

\section{RESULTS}

\section{Activities outside the colony}

Our observations at the breeding colony show that during the day the time spent foraging rises from $44 \%$ for incubating birds to $58 \%$ for birds with small chicks and to $65 \%$ for birds with downy chicks (Figs. 2 to 4 ). This corresponds to 425, 555 and $623 \mathrm{~min}$ spent every day outside of the colony for incubating birds and birds tending small and downy chicks respectively (for a mean day length of $16 \mathrm{~h}$ ). We also observed that the number of foraging trips per day was higher for birds with chicks than for incubating birds, i.e. a mean of $0.75 \mathrm{~d}^{-1}(\mathrm{SD}=0.7, \mathrm{n}=2)$ for incubating birds, $1.81 \mathrm{~d}^{-1}$ $(\mathrm{SD}=0.8, \mathrm{n}=26)$ for birds with small chicks and $2.81 \mathrm{~d}^{-1}(\mathrm{SD}=1.1, \mathrm{n}=16)$ for birds with downy chicks.

The mean flight distance for a foraging trip to the sea is $30 \mathrm{~km}$, whereas the birds fly only $5 \mathrm{~km}$ during a trip

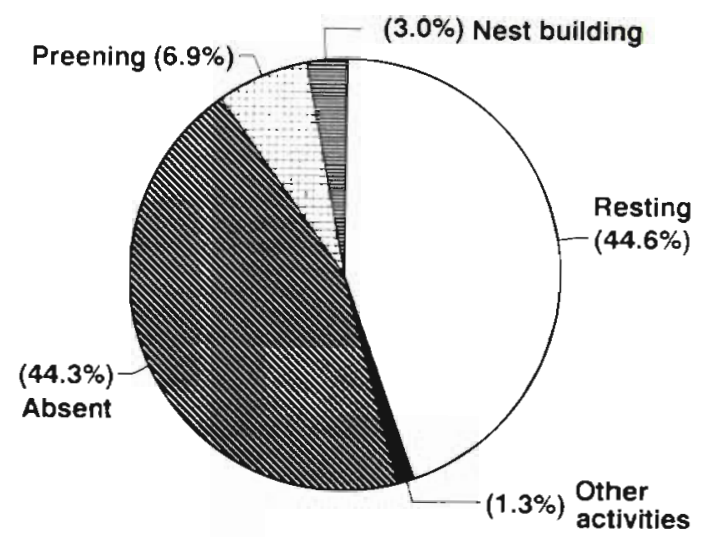

Fig. 2. Phalacrocorax carbo sinensis. Time budget of incubating great cormorants as observed at Lake Selent from dawn to dusk

on the lake. This results in a mean flight distance of $17.5 \mathrm{~km}$ per foraging trip. Considering the different numbers of foraging trips for the different breeding phases, a mean daily flight distance of $13.1 \mathrm{~km}$ for incubating birds ( 0.75 foraging trips $\left.\mathrm{d}^{-1}\right), 31.7 \mathrm{~km}$ for cormorants raising small chicks (1.81 trips $\mathrm{d}^{-1}$ ) and $49.2 \mathrm{~km}$ for cormorants with downy chicks (2.81 trips $\left.\mathrm{d}^{-1}\right)$ was calculated. The flight speed of great cormorants is $70 \mathrm{~km} \mathrm{~h}^{-1}$ (Van Dobben 1952, Géroudet 1959), which gives a daily flight time of 11 min for incubating birds, 27 min for birds with small chicks and 42 min for birds with downy chicks. Wind influence on flight time was ignored due to practical difficulties.

The cormorants observed feeding swam for a mean of $28 \mathrm{~min}(\mathrm{n}=21, \mathrm{SD}=5.3$ ). Considering this time as the mean swimming time for 1 foraging trip, we calculated that incubating birds swim a mean of $21 \mathrm{~min} \mathrm{~d}^{-1}$, cormorants with small chicks consequently swim 51 min and cormorants with downy chicks 79 min.

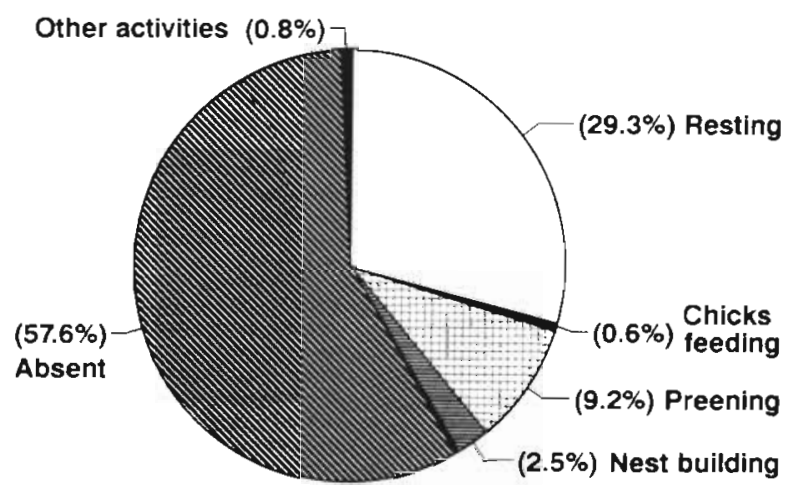

Fig. 3. Phalacrocorax carbo sinensis. Time budget of great cormorants with small chicks as observed at Lake Selent from dawn to dusk 


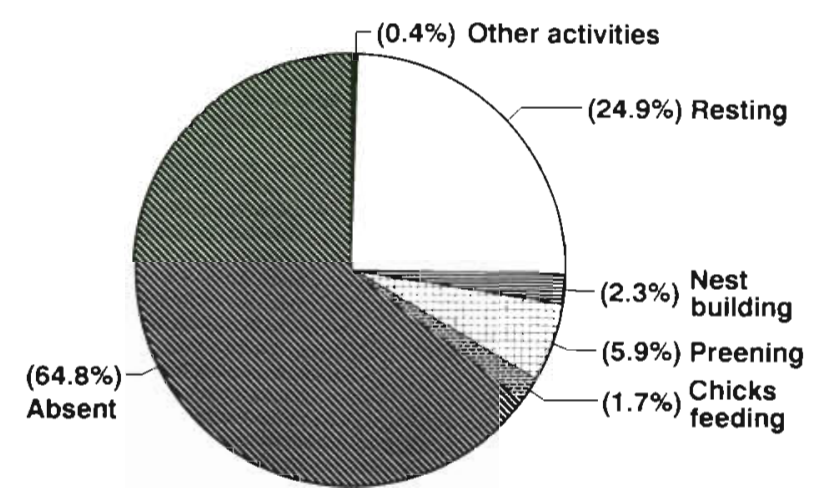

Fig. 4. Phalacrocorax carbo sinensis. Time budget of great cormorants raising downy chicks as observed at Lake Selent from dawn to dusk

Great cormorants stretch their wings for 6 min after each foraging trip (Menke 1986). We can thus predict a mean daily wing-stretching time of $5 \mathrm{~min}$ for incubating birds, and of 11 and 17 min for parents of small and downy chicks, respectively.

Flight, swimming and wing stretching only account for part of the time that great cormorants spend outside the colony $(37,89$ and 138 min daily for birds with eggs and small and downy chicks, respectively), the bulk of this time being spent resting and preening on sand banks near the fishing grounds $(388,466$ and $485 \mathrm{~min}$ daily for the different breeding phases). Assuming that cormorants spend $75 \%$ of this time resting and $25 \%$ preening (as observed at the colony), we can predict that they will rest outside the colony for 291,350 or $363 \mathrm{~min}^{-1}$ according to breeding phase, and correspondingly preen outside of the colony for 97,117 and $121 \mathrm{~min}$.

\section{Activities within the colony}

A total of $833 \mathrm{~h}$ of observations and 49 cormorantdays at the colony were recorded. The observed birds rested most of the time when on the nest (Figs. 2 to 4 ). Total daily resting time (in and outside of the colony) was thus calculated to be $718 \mathrm{~min}$ for incubating birds, $632 \mathrm{~min}$ for birds with small chicks and $602 \mathrm{~min}$ for birds with downy chicks. Additional observations at night showed that the cormorants always rested (480 min per $24 \mathrm{~h}$ in June) on the nest.

Total daily preening time (in and outside of the colony) was calculated to be 163, 205 or 178 min for cormorants with eggs or raising small or downy chicks, respectively.

Nest building was calculated to occupy $29 \mathrm{~min}$ of every day for incubating birds, 24 min for birds with small chicks and 22 min for those with downy chicks.
Small chicks were fed for 6 min every day, whereas downy chicks were fed for 16 min daily

Chicks were active only when feeding and remained the rest of the time in the 'energy conserving sleeping posture' described by Nelson (1978) in gannets

\section{Weather data}

Mean air temperature recorded at the breeding site was $15.5^{\circ} \mathrm{C}$ (range 10.5 to $26.3^{\circ} \mathrm{C}$ ), which is very similar to the $15.3^{\circ} \mathrm{C}$ recorded at Plön (20 km distant) for the same period. We therefore consider that these localities have comparable climates and that the mean air temperature between April and July as recorded in Plön $\left(12.5^{\circ} \mathrm{C}\right.$, range 6.6 to $\left.16.5^{\circ} \mathrm{C}\right)$ is a good indicator of the air temperature at the breeding site. This temperature also differed only slightly from the mean air temperature at the zoo $\left(12^{\circ} \mathrm{C}\right.$, range 4 to $\left.21^{\circ} \mathrm{C}\right)$ and at the feeding areas $\left(12.4^{\circ} \mathrm{C}\right.$, range 6.7 to $\left.16.3^{\circ} \mathrm{C}\right)$. Additionally, air temperature in the respiration chamber at the zoo never differed by more than $0.4^{\circ} \mathrm{C}$ from the outer temperature (due to the high flow rate)

Wind speed at the Plön station was stable over the breeding season $\left(\bar{x}=2.9 \mathrm{~m} \mathrm{~s}^{-1}, \mathrm{SD}=0.2\right)$ and we thus assume that the wind speeds measured at the colony represent those over the complete breeding season. Wind speeds were low (mean $1.6 \mathrm{~m} \mathrm{~s}^{-1}$ ) due to the location of the breeding colony in a small bay sheltered from wind by high trees. Wind was thus considered to play a minor role in the metabolism of birds sitting on the nest. Conversely, winds at the fishing grounds, especially along the coast of the Baltic Sea, which have a mean speed of $3.9 \mathrm{~m} \mathrm{~s}^{-1}$ (April to July; weather station Kiel-Holtenau) presumably significantly influence the metabolism of cormorants resting on a sand bank. Finally $44 \%$ of the days during the breeding season were considered 'sunny' (more than $120 \mathrm{~W} \mathrm{~m}^{-2}$ ) and $56 \%$ overcast.

Mean water temperature in the swimming canal was $12^{\circ} \mathrm{C}\left(11\right.$ to $\left.13.1^{\circ} \mathrm{C}\right)$, whereas the mean water temperature at the fishing ground during the breeding season is $11.3^{\circ} \mathrm{C}\left(5\right.$ to $17^{\circ} \mathrm{C}$ between April and July).

\section{Energy costs}

The daily energy budgets of adult great cormorants incubating or raising small or downy chicks are shown in Tables 1 to 3 . The mean RMR of the 5 great cormorants from the zoo was $24.7 \mathrm{~kJ} \mathrm{~h}^{-1}(\mathrm{SD}=2.3)$. Our weather data show that during the breeding season (April to July) the sun shines for $42 \%$ of the daylight hours. We thus use a RMR of $23.7 \mathrm{~kJ} \mathrm{~h}^{-1}$ for daytime. At night, a reduction of $25 \%$ in the RMR as measured at 
Table 1. Phalacrocorax carbo sinensis. Daily energy budget (DEB) of an incubating great cormorant from Lake Selent. Three eggs per clutch are assumed. See text for further explanation

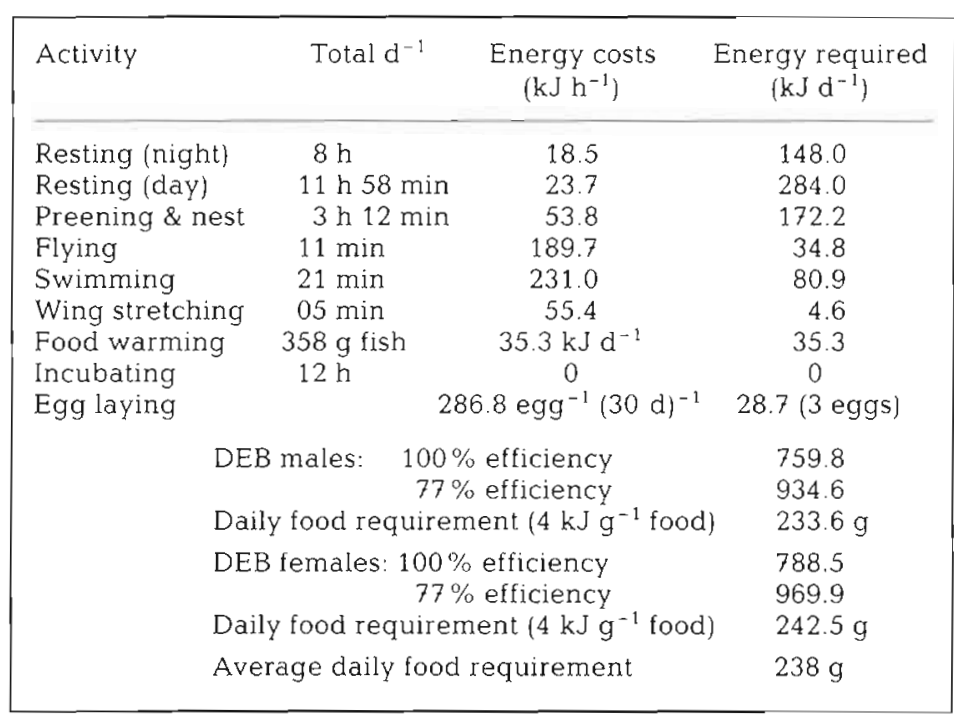

the zoo results in a RMR of $18.5 \mathrm{~kJ} \mathrm{~h}^{-1}$. The energy costs of feeding small and downy chicks are $27.2 \mathrm{~kJ} \mathrm{~h}^{-1}$ (1.10 RMR) and $37.8 \mathrm{~kJ} \mathrm{~h}^{-1}$ (1.53 RMR) respectively.

The energy costs of preening and nest building were calculated to be $53.8 \mathrm{~kJ} \mathrm{~h}^{-1}(\mathrm{n}=5, \mathrm{SD}=7.0)$ and thus correspond to $2.18 \mathrm{RMR}$.

Flight costs without 'parasitic load' were calculated to be $189.7 \mathrm{~kJ} \mathrm{~h}^{-1}$. Incubating birds foraging less than once a day consequently spend extended periods resting and preening near the feeding areas (388 min). This time is sufficient to digest all the fish eaten. We thus consider that there is no parasitic load for incubating birds, and take mean flight costs to be $189.7 \mathrm{~kJ}$ $\mathrm{h}^{-1}$. Cormorants with small chicks spend less time resting and preening before they return to their nests and certainly have to carry part of the ingested food back to the brood. We thus assumed a general parasitic food load of $100 \mathrm{~g}$ for birds returning to the colony when raising chicks, which results in mean flight costs of $195.1 \mathrm{~kJ} \mathrm{~h}^{-1}$.

Swimming costs in great cormorants as measured in the zoo varied according to swimming speed. The mean swimming speed in the canal was $1.53 \mathrm{~m} \mathrm{~s}^{-1}$ (SD $=0.23$, range 0.5 to $3 \mathrm{~m} \mathrm{~s}^{-1}$ ), with usual speeds of between 1.3 and $1.7 \mathrm{~m} \mathrm{~s}^{-1}$. These results are related to the mean swimming speed of great cormorants in the wild which is considered to be $1.5 \mathrm{~m} \mathrm{~s}^{-1}$ (Johnsgard 1993). We thus assumed mean swimming costs of $231 \mathrm{~kJ} \mathrm{~h}^{-1}$, which is the mean energy cost for swimming speeds between 1.3 and $1.7 \mathrm{~m} \mathrm{~s}^{-1}$.
An amount of $54.8 \mathrm{~kJ}$ is required to warm $358 \mathrm{~g}$ fish caught at $11.3^{\circ} \mathrm{C}$ to the body temperature of cormorants. We also calculated that birds produce $19.5 \mathrm{~kJ}$ of heat during the 45 min after fishing when incubating. This amount rises to 21.3 and $23 \mathrm{~kJ}$ when the birds have small and downy chicks, respectively. Cormorants are therefore predicted to have an overall energy expenditure of $35.3 \mathrm{~kJ} \mathrm{~d}^{-1}$ for food warming when incubating and of 33.5 and $31.8 \mathrm{~kJ}$ when raising small and downy chicks, respectively.

The cost of laying eggs was calculated to be $286.8 \mathrm{~kJ} \mathrm{egg}^{-1}$ and consequently $860.4 \mathrm{~kJ}$ for a clutch of 3 . These costs were considered to be incurred over the total incubation period (30 d; Dif 1982) and thus represent daily energy costs of $28.7 \mathrm{~kJ}$ for female great cormorants.

Incubation costs calculated according to Kendeigh et al. (1977) are $678 \mathrm{~J} \mathrm{~h}^{-1}$ and the costs of brooding chicks $8.6 \mathrm{~kJ} \mathrm{~h}^{-1}$. However, we considered that incubating cormorants metabolise $27.7 \mathrm{~kJ} \mathrm{~h}^{-1}$ (resting, preening and nest building) and consequently produce $20.7 \mathrm{~kJ}$ heat $\mathrm{h}^{-1}$. This amount of energy is sufficient to keep eggs or chicks warm. We consequently assume that no additional energy costs are required for these 2 activities.

\section{Energy budget of chicks}

The RMR of small chicks as determined by Dunn (1976) is $4.3 \mathrm{~kJ} \mathrm{~h}^{-1}$. The daily energy budget (DEB) of 1 of these chicks consequently involves $25.6 \mathrm{~kJ}$ for rest at

Table 2. Phalacrocorax carbo sinensis. Daily energy budget (DEB) of a great cormorant from Lake Selent while raising small chicks. Two chicks per brood are assumed. See text for further explanation

\begin{tabular}{|c|c|c|c|}
\hline Activity & Total $d^{-1}$ & $\begin{array}{l}\text { Energy costs } \\
\qquad\left(\mathrm{kJ} \mathrm{h}^{-1}\right)\end{array}$ & $\begin{array}{c}\text { Energy required } \\
\qquad\left(\mathrm{kJ} \mathrm{d}^{-1}\right)\end{array}$ \\
\hline Resting (night) & $8 \mathrm{~h}$ & 18.5 & 148.0 \\
\hline Resting (day) & 10 h $32 \mathrm{~min}$ & 23.7 & 249.6 \\
\hline Preening \& nest & 3 h $49 \mathrm{~min}$ & 53.8 & 205.3 \\
\hline Flying & $27 \min$ & 195.1 & 87.8 \\
\hline Swimming & $51 \mathrm{~min}$ & 231.0 & 196.4 \\
\hline Wing stretching & $11 \min$ & 55.4 & 10.2 \\
\hline Food warming & $358 \mathrm{~g}$ fish & $33.5 \mathrm{~kJ} \mathrm{~d}^{-1}$ & 33.5 \\
\hline Brooding & $12 \mathrm{~h}$ & 0 & 0 \\
\hline Chick feeding & $6 \mathrm{~min}$ & 27.2 & 2.7 \\
\hline \multicolumn{3}{|c|}{ DEB chick } & 94.5 \\
\hline \multicolumn{3}{|c|}{$\begin{array}{l}\text { DEB chick + DEB parent } \\
77 \% \text { efficiency }\end{array}$} & $\begin{array}{l}1028.1 \\
1264.6\end{array}$ \\
\hline \multicolumn{3}{|c|}{ Daily food requirement $\left(4 \mathrm{~kJ} \mathrm{~g}^{-1}\right.$ food) } & $316 \mathrm{~g}$ \\
\hline
\end{tabular}


Table 3. Phalacrocorax carbo sinensis. Daily energy budget (DEB) of a great cormorant from Lake Selent while raising downy chicks. Two chicks per brood are assumed. See text for further explanātion

\begin{tabular}{|c|c|c|c|}
\hline Activity & Total $d^{-1}$ & $\begin{array}{l}\text { Energy costs } \\
\quad\left(\mathrm{kJ} \mathrm{h}^{-1}\right)\end{array}$ & $\begin{array}{l}\text { Energy required } \\
\qquad\left(\mathrm{kJ} \mathrm{d} \mathrm{d}^{-1}\right)\end{array}$ \\
\hline Resting (night) & $8 \mathrm{~h}$ & 18.5 & 148.0 \\
\hline Resting (day) & $10 \mathrm{~h} 02 \mathrm{~min}$ & 23.7 & 237.8 \\
\hline Preening \& nest & 3 h $20 \mathrm{~min}$ & 53.8 & 179.3 \\
\hline Flying & $42 \min$ & 195.1 & 136.6 \\
\hline Swimming & 1 h $19 \min$ & 231.0 & 304.2 \\
\hline Wing-stretching & $17 \min$ & 55.4 & 15.7 \\
\hline Food warming & $358 \mathrm{~g}$ fish & $31.8 \mathrm{~kJ} \mathrm{~d}^{-1}$ & 31.8 \\
\hline Brooding & $12 \mathrm{~h}$ & 0 & 0 \\
\hline Chick feeding & $16 \mathrm{~min}$ & 37.8 & 10.1 \\
\hline \multicolumn{3}{|c|}{ DEB chick } & 853.9 \\
\hline \multicolumn{3}{|c|}{$\begin{array}{l}\text { DEB chick + DEB parent } \\
77 \% \text { efficiency }\end{array}$} & $\begin{array}{l}1913.3 \\
2353.3\end{array}$ \\
\hline \multicolumn{3}{|c|}{ Daily food requirement $\left(4 \mathrm{~kJ} \mathrm{~g}^{-1}\right.$ food) } & $588 \mathrm{~g}$ \\
\hline
\end{tabular}

this problem: (1) The use of stomach temperature probes as first described by Wilson et al. (1992) can deliver information about the mass of single prey ingested with an accuracy of $80 \%$ (Grémillet \& Plös 1994). However, the price of the devices and their high rejection rate by cormorants at sea reduces sample size and thus makes predictions about the food consumption of an entire population difficult. (2) The DEB can also be determined by using doubly labeled water (DLW). This method has an accuracy of $92 \%$ (Nagy 1989) but also involves substantial financial costs and has several drawbacks: in particular, the birds have to be caught twice within a short period of time which is very difficult in the case of great cormorants. Additionally, Wilson \& Culik (in press) have shown that injection of DLW may significantly alter foraging parameters. (3) Records

night (with an RMR of $0.75 \times 4.3=3.2 \mathrm{~kJ}$ ), $68.4 \mathrm{~kJ}$ for rest during the day and $0.54 \mathrm{~kJ}$ for feeding activities (with an RMR of $1.25 \times 4.3=5.4 \mathrm{~kJ}$ ). This results in a DEB of $94.5 \mathrm{~kJ}$ per chick and of $189.1 \mathrm{~kJ}$ for a brood of 2 chicks.

The DEB of 1 downy chick can be calculated in a similar manner: $599.7 \mathrm{~kJ}$ is used at rest during the day (with an RMR of $39.9 \mathrm{~kJ} \mathrm{~h}^{-1}$ ), $239.2 \mathrm{~kJ}$ for rest at night (with an RMR of $0.75 \times 39.9=29.9 \mathrm{~kJ} \mathrm{~h}^{-1}$ ) and $15 \mathrm{~kJ}$ for feeding activities (with an RMR of $1.25 \times$ $39.9=49.9 \mathrm{~kJ} \mathrm{~h}^{-1}$ ). The DEB of a brood of 2 downy chicks is consequently $2 \times 853.9=1707.8 \mathrm{~kJ}$.

The energy requirements of the brood are assumed to be equally divided between the 2 parents.

Assuming that the birds incubate for $30 \mathrm{~d}$ (Dif 1982) and then raise their chicks for $50 \mathrm{~d}$, during which time the chicks are small for $10 \mathrm{~d}$ and downy for $40 \mathrm{~d}$, the mean food intake of 1 breeding great cormorant can be calculated to be $428 \mathrm{~g}_{\text {fish }} \mathrm{d}^{-1}$. In 1993, 503 great cormorant nests were counted at the breeding site at Lake Selent. Assuming a population of $2 \times 503=1006$ birds, a daily fish consumption of $428 \mathrm{~g}$ and a breeding period of $80 \mathrm{~d}$, we can predict that the entire colony may need ca 34 metric tons of fish every breeding season, of which ca $17 \mathrm{t}$ is likely to be taken from the lake and ca $17 \mathrm{t}$ from the Baltic Sea.

\section{DISCUSSION}

Direct quantification of the daily food intake in cormorants through pellet or stomach content analysis has been shown to be problematic (Grémillet \& Plös 1994). There are 5 further methods available to solve of heart rate can also be used to determine the energy requirements of free-living birds; however, this method requires that recording devices be implanted, with associated trauma. (4) Allometric relationships, which have already been used in order to determine the DEB of free-living great cormorants (Reichholf 1990, Voslamber \& Van Eerden 1991, Wißmath et al. 1993), have an accuracy of only $60 \%$ (Weathers et al. 1984). (5) Different studies, in which both DLW and time budget methods have been deployed, show that, under certain conditions, a time budget analysis may also deliver highly accurate results. Weathers et al. (1984) and Buttemer et al. (1986) show for example that the DEB of loggerhead shrikes Lanius ludovicianus and budgerigars Melopsittacus undulatus as determined by DLW injection and time budget analysis differ only by 8 and $4 \%$, respectively. Nagy (1989) noted that deviation between the results of these 2 methods should be smaller in larger birds as they are less sensitive to weather conditions. This was the case in Adélie penguins studied by Culik (1995) who found a difference of only $1 \%$ between the results of the DLW study and the time budget analysis, and in the jackass penguin where DLW estimates of the energy budget (Nagy et al. 1984) were within 3\% of previous bioenergetic estimates (Furness \& Cooper 1982).

The energy budget presented here is a first attempt at a quantification of the daily food intake in great cormorants using a time/energy budget. Important assumptions had to be made concerning the timing of certain activities or their costs. In particular activity patterns of the birds outside the colony and the influence of environmental factors such as wind speed on the metabolism are not sufficiently known. 
Nevertheless, we consider that the energy expended by breeding great cormorants for activities within the colony, reproduction, swimming in cold water and eating cold food have been accurately determined, these costs, as shown in Fig. 5, represent $75.9 \%$ of the DEB in breeding adults. A sensitivity analysis shows that a doubling of the daily flight costs, which could result from higher flight costs or longer flight times, would lead to an increase in daily food intake of only $30 \mathrm{~g}$. A doubling of the daily swimming costs, which could arise as a result of birds foraging more than once per trip, or longer when feeding on Lake Selent, leads to an increase in daily food intake of $60 \mathrm{~g}$.

A daily ration of $500 \mathrm{~g}$ is traditionally assumed necessary for great cormorants (Bauer \& Glutz 1966, Müller 1986, Deufel 1987, Zimmermann 1989). In the present study the mean food consumption over the complete breeding season was calculated to be $423 \mathrm{~g}$ bird $^{-1} \mathrm{~d}^{-1}$. This is little different from the $500 \mathrm{~g}$ assumed by most authors; however, such fish consumption has to be seen as a maximum which occurs during less than one-third of the year. The rest of the time food requirements of non-breeders under the same meteorological conditions should be very similar to the requirements of incubating birds. These were calculated to be $238 \mathrm{~g} \mathrm{~d}^{-1}$, less than half of the assumed $500 \mathrm{~g}$.

The time budget used for the present determination of the daily food intake in great cormorants does not include activity patterns resulting from disturbances at the breeding or the resting sites. This kind of intervention usually causes the birds to leave the colony for about 30 min (Grémillet pers. obs.). During this time, the cormorants stay for about 10 min on the water surface several hundred metres away from the colony (Menke 1986, authors' pers. obs.), after which they return to the breeding site, flying around for at least $15 \mathrm{~min}$ before landing. This results in energy costs of $63.2 \mathrm{~kJ}$ for flight and $18.8 \mathrm{~kJ}$ for resting on the water surface. The overall costs are, therefore, $82 \mathrm{~kJ}$ bird $^{-1}$, an increase of $69.7 \mathrm{~kJ}$ above those for resting. This converts to $23 \mathrm{~g}$ fish which must be additionally eaten per disturbed cormorant. In a colony of 1000 birds, a single disturbance may result in an additional fish consumption of $23 \mathrm{~kg}$, enough to feed a breeding cormorant during the entire breeding season. This confirms the fact that human presence at resting or breeding sites is not an efficient way of reducing the predation of cormorants on fish stocks (see also Kieckbusch \& Koop 1992)
Acknowledgements. This study was supported by the Ministerium für Natur, Umwelt und Landesentwicklung des Landes Schleswig-Holstein, the Institut für Meereskunde an der Universität Kiel and the Groupe Ornithologique Normand. Grateful thanks are due to A. Rüger, D. Adelung, W. Knief, P. Drüwa and the staff of the Heimattierpark Neumünster. We also thank $M$. Kierspel, J. Kieckbusch, $B$. Koop, T Menke, T. Keller, K. \& N. John, R. Wilson, G. Peters and $K$. Putz for their extensive support.

\section{LITERATURE CITED}

Ackermann RA, Seagrave RC (1984) Parent-egg interactions: egg temperature and water loss. In: Whittow GC, Rahn H (eds) Seabird energetics. Plenum Press, New York, p 59-72

Aschoff J, PohI H (1970) Der Ruheumsatz von Vögeln als Funktion der Tageszeit und der Körpergröße. J Ornithol 111:38-47

Bauer KM, Glutz von Blotzheim UN (1966) Handbuch der Vögel Mitteleuropas. Bd 1. Akademische Verlagsgesellschaft, Frankfurt am Main

Brugger K (1993) Digestibility of three fish species by doublecrested cormorants. Condor 95:25-32

Buttemer WA, Hayworth AM, Weathers WW, Nagy KA (1986) Time energy budget estimates of avian energy expenditure: physiological and meteorological considerations. Physiol Zool 59:131-149

Cooper J (1987) Biology of the Bank cormorant, part 5: clutch size, eggs and incubation. Ostrich 58(1):1-8

Culik B (1995) Energy expenditure of Adélie Penguins. In: Dann P, Normann I, Reily P (eds) Penguins. Surrey Beatty, Sydney, p 177-195

Culik B, Wilson RP (1991) Energetics of under-water swimmıng in Adélie Penguins (Pygoscelis adeliae). J comp Physiol B 161:285-291

Culık B. Woakes AJ, Adelung D, Wilson RP, Coria NR, Spairani HJ (1990) Energy requirements of Adélie Penguin (Pygoscelis adeliae) chicks. J comp Physiol B 160 $61-70$

Deufel J (1987) Kormorane - Eine Gefahr für unsere Fische Fischwirt 37(7-8):49-54

Dif G (1982) Les oiseaux des mers d'Europe. Edıtions Arthaud, Paris

Dunn EH (1976) Development of endothermy and existence 
energy expenditure of nestling Double-crested cormorants. Condor 78:350-356

Furness R, Cooper J (1982) Interactions between breeding seabirds and pelagic fish populations in the southern Benguela region. Mar Ecol Prog Ser 8:243-250

Géroudet $P$ (1959) Les palmipèdes. Delachaux et Niestlé. Neuchâtel-Paris

Gregersen J (1991) The development of the Danish cormorant population 1980-88 and some comments on the breeding success. In: Van Eerden MR, Zijlstra M (eds) Proceedings workshop 1989 on cormorants Phalacrocorax carbo. Ministerie van Verkeer en Waterstaat, Lelystad, p 36-38

Gremillet D. Plös A (1994) The use of stomach temperature records for the calculation of daily food intake in cormorants. J exp Biol 189:105-115

Grémillet D, Schmid D (1993) Zum Nahrungsbedarf des Kormorans Phalacrocorax carbo sinensis. Bericht des Ministeriums für Natur, Umwelt und Landesentwicklung des Landes Schleswig-Holstein, Kiel

Hashmi D (1988) Ökologie und Verhalten des Kormorans (Phalacrocorax c. sinensis) im Ismaninger Teichgebiet. Anz Ornithol Ges Bayern 27:1-44

Hennemann WW (1983) Environmental influences on the energetics and behavior of Anhingas and Double-crested cormorants. Physiol Zool 56:201-216

Hislop JRG. Harris MP, Smith JG (1991) Variation in the calorific value and total energy content of the lesser sandeel (Ammodytes marinus) and other fish preyed on by seabirds. J Zool Lond 224:501-517

Johnsgard PA (1993) Cormorants, darters and pelicans of the world Smithsonian Institution Press, Washington

Kendeigh SC, Blem CR (1974) Metabolic adaptations to local climate in birds. Comp Biochem Physiol 48A:175-187

Kendeigh SC, Dol'nik VR, Gavrilov VM (1977) Avian energetics. In: Pinowski J, Kendeigh SC (eds) Granivorous birds in ecosystems. Cambridge University Press, Cambridge, p 127-204

Kieckbusch J, Koop B (1992) Ornithologische Begleituntersuchungen zum Kormoran. Bericht des Ministeriums für Natur, Umwelt und Landesentwicklung des Landes Schleswig-Holstein, Kiel

Kieckbusch J, Koop B (1993) Ornithologische Begleituntersuchungen zum Kormoran. Bericht des Ministeriums für Natur, Umwelt und Landesentwicklung des Landes Schleswig-Holstein, Kiel

King JR (1973) Energetics of reproduction in birds. In: Farner DS (ed) Breeding biology of birds. National Academy of Science, Washington, DC, p 78-107

Klaassen M. Drent R (1991) An analysis of hatchling resting metabolism. In search of ecological correlates that explain deviations from allometric relations. Condor 93: 612-629

Knief W, Witt H (1983) Zur Situation des Kormorans (Phalacrocorax carbo) in Schleswig-Holstein und Vorschläge für seine künttge Behandlung. Ber Deutsch Sekt Int Rat Vogelschutz 23:67-79

Kortlandt A (1991) Patterns of pair formation and nestbuilding in the European cormorant. In: Van Eerden MR, Zij]stra $M$ (eds) Proceedings workshop 1989 on cormorants Phalacrocorax carbo. Ministerie van Verkeer en Waterstaat, Lelystad, p 11-26

Marteijn ECL, Dirksen S (1991) Cormorants Phalacrocorax carbo sinensis feeding in shallow eutrophic freshwater lakes in the Netherlands in the non-breeding period: prey choice and fish consumption. In: Van Eerden MR, Zijlstra
M (eds) Proceedings workshop 1989 on cormorants Phalacrocorax carbo. Ministerie van Verkeer en Waterstaat, Lelystad. p 135-155

Menke T (1986) Untersuchungen zur Biologie und Bestandsentwicklung des Kormorans (Phalacrocorax carbo sinensis) in Schleswig-Holstein von 1984-1986. MSc thesis Kiel Unıversily

Müller R (1986) Die Nahrung des Kormorans (Phalacrocorax carbo sinensis) am Bodensee. 'Petr-Heil'-Beilage, Schwoir Fischereiwissenschaft $3(1): 1-2$

Nagy KA (1989) Field bioenergetics: accuracy of models and methods. Physiol Zool 62(2):237-252

Nagy KA, Siegfried WR, Wilson RP (1984) Energy utilisation by free-ranging Jackass Penguins, Spheniscus demersus Ecology 65(5): 1648-1655

Nelson B (1978) The gannet. T \& AD Poyser, Berkhamsted

Pennycuick CJ (1989) Bird flight performance. A practical calculation manual. Oxford University Press, Oxford

Platteeuw M, Koffijberg K, Dubbeldam W (in press) Growth and energy needs of cormorant Phalacrocorax carbo sinensis chicks in relation to brood size and parental fishing effort. Ardea

Reichholf J (1990) Verzehren überwinternde Kormorane (Phalacrocorax carbo) abnorm hohe Fischmengen? Mitt Zool Ges Braunau 5(9/12):165-174

Schmidt-Nielsen K (1983) Animal physiology: adaptation and environment. Cambridge University Press, London

Schweimer M (1978) Physikalische-ozeanographische Parameter in der westlichen Ostsee -- Eine Literaturstudie. Ber lnst Meeresk Kiel 61:20

Sidwell VD (1981) Chemical and nutritional composition of finfishes, whales, crustaceans, mollusks and their products. NOAA tech Mem NMFS F/SEC-11

Suter W (1989) Bestand und Verbreitung in der Schweiz überwinternder Kormorane Phalacrocorax carbo. Ornithol Beob 86:25-52

Van Dobben WH (1952) The food of the cormorant in the Netherlands. Ardea 11:1-34

Voslamber B, van Eerden MR (1991) The habit of mass flock fishing by cormorants Phalacrocorax carbo sinensis at the Ijsselmeer, the Netherlands. In: Van Eerden MR, Zijlstra M (eds) Proceedings workshop 1989 on cormorants Phalacrocorax carbo. Ministerie van Verkeer en Waterstaat Lelystad, p 182-191

Weathers W, Buttemer W, Hayworth A. Nagy KA. (1984) An evaluation of time-budget estimates of daily energy expenditure in birds. Auk 101:459-472

Wilson RP, Cooper J, Plötz J (1992) Can we determine when marine endotherms feed? A case study with seabirds. $\mathrm{J} \exp$ Biol 167:267-275

Wilson RP, Culik BM (1991) The cost of a hot meal: facultative specific dynamic action may ensure temperature homeostasis in post-ingestive endotherms. Comp Biochem Physiol 100A(1):151-154

Wilson RP, Culik BM (in press) Energy studies of free-living seabirds: do injections of doubly-labelled water affect gentoo penguin behaviour. J Field Ornithol

Wil3math P, Wunner U, Pavlinec M (1993) Kormorane in Bayern-Bereicherung der Natur oder eine Plage? Fischer Teichwirt 7:238-244

Worthmann H, Spratte S (1990) Nahrungsuntersuchungen an Kormoranen vom Großen Plöner See. Fischer Teichwirt $41(1): 2-8$

Zimmermann H (1989) Kormoran, Phalacrocorax carbo, und Fischerei in der DDR. Beitr Vogelkd 35(1/4):193-198 